\title{
Dispositivo vestível para auxiliar alunos tetraplégicos em ambientes escolares.
}

\author{
Marcelo M. da Silva, Pedro H. G. Muniz, Francisco C. de M. B. Oliveira, Lidiane \\ C. Silva, Éder F. Soares
}

Centro de Pesquisa, Desenvolvimento e Inovação Dell - Lead - Universidade Estadual do Ceará (UECE)

\{marcelo.martins, pedro.muniz, fran, lidcastro\}@dellead.com, ederfurtado@gmail.com

\section{Introdução}

De acordo com dados do censo de 2010 do Instituto Brasileiro de Geografia e Estatística (IBGE), há no Brasil mais de 45 milhões de pessoas com algum tipo de deficiência. Dentre elas, podemos destacar a deficiência motora, que afeta pelo menos 3,15 milhões de pessoas (IBGE, 2010). Já o Censo Escolar de 2016 aponta que 57,8\% das escolas brasileiras têm alunos com deficiência incluídos em classes comuns (INEP, 2017).

Segundo Tomelin (2018) na educação inclusiva, é responsabilidade das escolas reconhecer e atender às necessidades individuais de seus estudantes, adaptando-se aos vários ritmos de aprendizagem, de modo a garantir uma educação de qualidade para todos por meio de estratégias pedagógicas, de utilização de recursos e de cooperação com as respectivas comunidades.

A Lei $n^{\circ}$ 13.146, também conhecida como Lei Brasileira de Inclusão da Pessoa com Deficiência, estabelece as condições de igualdade, os direitos e as liberdades fundamentais, que busca incluí-la, definitivamente, como cidadã (BRASIL, 2015). Todavia, a falta de acessibilidade é um desafio para todas as deficiências, pois pessoas com deficiência $(\mathrm{PcD})$ precisam enfrentar a falta de acessibilidade nos transportes públicos, nos prédios públicos e privados, em universidades, e em espaços públicos.

Pessoas com tetraplegia, que possuem limitações motoras nos membros inferiores e superiores, encontram grande dificuldade para navegar em um computador, o que torna mais árdua tanto sua formação educacional básica quanto sua qualificação profissional. Em contrapartida, a área de tecnologia da informação, na qual grande parte das tarefas não requer que se trabalhe em pé ou se movimente muito, tem grande potencial para absorver essa força de trabalho. Além disso, as pesquisas com tecnologias assistivas avançam progressivamente na busca de desenvolver soluções que possam auxiliar nas atividades do cotidiano de pessoas com deficiência. "Tecnologia Assistiva" (TA) é um termo geral utilizado para identificar os recursos e serviços que contribuem para proporcionar ou ampliar habilidades funcionais de pessoas com deficiência e, por consequência, oferecer a elas uma vida independente e de maior inclusão (BERSCH; TONOLLI, 2006).

Muitas tecnologias existentes que são propostas para auxiliar pessoas tetraplégicas fazem uso de visão de computador para realizar os cliques do mouse. É o caso dos chamados "Glasses Mouses", dos quais tratam Rodrigues et al (2016), mas esses dispositivos são muito susceptíveis a erros na captação dos movimentos dos olhos, 
o que torna a navegação difícil. Além disso, o usuário não tem liberdade de se movimentar para além do campo de captação de imagem da câmera. $\mathrm{O}$ usuário tende a ficar bastante limitado também com dispositivos que usam movimentos da boca ou da língua para movimentar o cursor, como é o caso do dispositivo apresentado por Nutt et al. (2019). Utilizando-se apenas de movimentos da cabeça e das bochechas, nossa solução evita esse tipo de problema. Fizemos uma pesquisa da literatura especializada e promovemos sessões de discussões com pessoas com tetraplegia com o intuito de desenvolver e validar o conceito de uma proposta que fosse intuitiva e ergonomicamente adequada as suas necessidades. Propomos neste trabalho uma ferramenta especialmente desenvolvida para habilitar alunos com tetraplegia a usar um computador com mais liberdade, tanto para sua formação básica e profissional quanto em um ambiente de trabalho: trata-se de um dispositivo vestível que capta movimentos naturais da cabeça para desempenhar todas as funções de um mouse comum.

\section{Dispositivo vestível para a promoção de acessibilidade}

Propomos um dispositivo para auxiliar alunos tetraplégicos com a navegação em desktops para a realização de atividades escolares que necessitem de computadores. $\mathrm{O}$ dispositivo tem o formato de um headset e as funções de um mouse. Ele possui sensores que fazem a captura dos movimentos da cabeça do usuário e processam esses dados em tempo real. Movimentos para os lados, para cima e para baixo são controlados por um acelerômetro e os cliques são feitos com movimentos das bochechas, que tocam em dois sensores touch switch. A Figura 1 apresenta a visão geral do dispositivo.

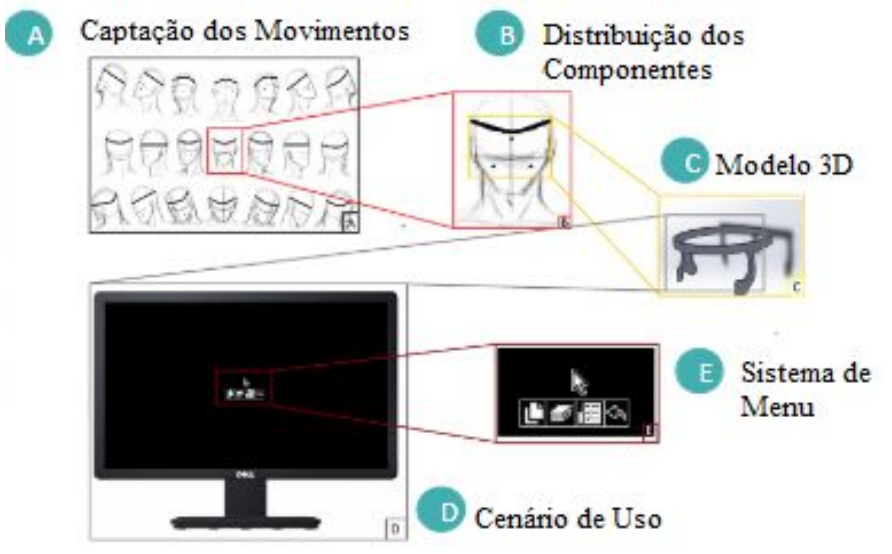

Figura 1: Visão geral do dispositivo no usuário.

O dispositivo é composto por duas partes, uma eletrônica e uma física. Para o desenvolvimento da parte eletrônica, utilizamos um módulo com acelerômetro e giroscópio para capturar os movimentos feitos pela cabeça do usuário nas posições $\mathrm{X}, \mathrm{Y}$ e Z, garantindo o movimento do cursor na tela. Sensores touch são utilizados para captar os movimentos das bochechas e realizar os cliques direito e esquerdo do mouse.

A parte física do dispositivo foi impressa em 3D e, como todas as partes do dispositivo, tem um baixo custo de fabricação. Ela tem o formato semelhante ao de um headset, e é utilizada principalmente para a alocação e organização dos componentes eletrônicos que foram utilizados no desenvolvimento. A figura 2 apresenta um modelo 3D do dispositivo, e o mesmo impresso, já com as tiras de velcro para suporte na parte 
superior da cabeça do usuário. Optamos pelo velcro por ser um material barato, durável e de fácil substituição, em caso de necessidade.

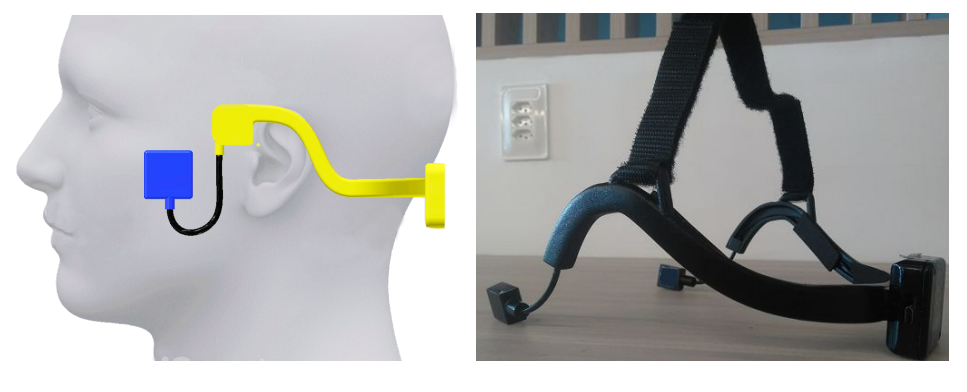

Figura 2 : Impressão 3D do dispositivo

\section{Resultados preliminares e Considerações Finais}

Foram feitos testes de inspeção do primeiro protótipo em laboratório com bons resultados e, neste momento, estamos preparando testes com pessoas sem tetraplegia para avaliar tanto o funcionamento do dispositivo quanto sua ergonomia. Estamos elaborando um questionário sobre ergonomia e conforto e, depois dos novos testes, possivelmente precisaremos da participação de especialistas em design para implementar adaptações em um novo protótipo. Acreditamos que uma das ações possíveis para enfrentar o problema da inclusão de $\mathrm{PcD}$ em ambientes de educação formal passam também pela inovação tecnológica. E em um projetos desse tipo, é essencial contar com o trabalho harmonioso de equipes multidisciplinares.

\section{Referências}

Bersch, R. e Tonolli, J. C. (2006) Introdução ao conceito de Tecnologia Assistiva e modelos de abordagem da deficiência. Porto Alegre: CEDI - Centro Especializado em Desenvolvimento Infantil.

Brasil. (2015) Lei no 13.146, de 06 de julho de 2015. "Institui a Lei Brasileira de Inclusão da Pessoa com Deficiência”, Diário Oficial da União.

IBGE. (2010) Censo Demográfico 2010. Brasília. Disponível em: http://www.ibge.gov.br. Acesso em: 20 de julho de 2019.

INEP. (2017) Censo Escolar da Educação Básica 2016: Notas Estatísticas. Brasília. INEP. Disponível em: http://portal.inep.gov.br/web/guest/publicacoes. Acesso em: 20 de julho de 2019.

Nutt, W. et al. (2019) "Tongue-mouse for quadriplegics". In: Journal of Micromechanics and Microengineering, vol. 8, n. 2.

Rodrigues A. S. et al. (2016) "Evaluation of the Use of Eye and Head Movements for Mouse-like Functions by Using IOM Device". In: Universal Access in Human-Computer Interaction. Interaction Techniques and Environments. Editado por Antona M. e Stephanidis C., Springer.

Tomelin, K. N. et al. (2018) "Educação inclusiva no ensino superior: desafios e experiências de um núcleo de apoio discente e docente". In: Rev.w psicopedag., São Paulo, v. 35, n. 106, p. 94-103. 